CNS Spectrums (2019), 24, 322-332. C Cambridge University Press 2017. The online version of this article is published within an Open Access environment subject to the conditions of the Creative Commons Attribution-NonCommercial-ShareAlike licence $<$ http://creativecommons.org/licenses/by-nc-sa/4.0/>. The written permission of Cambridge University Press must be obtained for commercial re-use.

doi:10.1017/S1092852917000633

\title{
Categorical improvement in functional impairment in depressed patients treated with desvenlafaxine
}

\author{
Claudio N. Soares, ${ }^{1,2 *}$ Min Zhang, ${ }^{3}$ and Matthieu Boucher ${ }^{4}$
}

\author{
${ }^{1}$ Professor of Psychiatry, Queen's University School of Medicine, Kingston, Ontario, Canada \\ ${ }^{2}$ St. Michael's Hospital, University of Toronto, Toronto, Ontario, Canada \\ ${ }^{3}$ Director of Clinical Statistics, Pfizer Inc, New York, New York, United States \\ ${ }^{4}$ Medical Affairs, Pfizer Canada Inc, Kirkland, Quebec, Canada
}

Objective. This post-hoc pooled analysis evaluated categorical change in functional impairment in patients with major depressive disorder (MDD) treated with desvenlafaxine versus placebo and examined whether early improvement in functioning predicted functional outcomes at study endpoint.

Methods. Data were pooled from eight randomized, double-blind, placebo-controlled studies of desvenlafaxine for the treatment of MDD, including adults who were randomly assigned to receive desvenlafaxine $50 \mathrm{or} 100 \mathrm{mg} / \mathrm{d}$ or placebo $(N=3,384)$. Shift tables were generated for categorical changes in functional impairment from baseline based on Sheehan Disability Scale (SDS) subscale scores. The categories were none/mild (0-3), moderate (4-6), and marked/ extreme (7-10). Treatment comparisons for prespecified shifts of interest and predictive value of week 2 or 4 improvement in SDS subscale scores for functional outcome at week 8 were assessed using logistic regression.

Results. Greater proportions of patients receiving desvenlafaxine 50 and $100 \mathrm{mg}$ achieved improvement from baseline to week 8 for each prespecified shift endpoint versus placebo (all $p \leq 0.02$ ). Early improvement in SDS subscale scores was a statistically significant predictor of functional outcome at week 8, both overall and for each treatment group (all $p<0.0001$ ).

Conclusions. Treatment with desvenlafaxine 50 or $100 \mathrm{mg} / \mathrm{d}$ led to significantly greater categorical improvement in functional impairment versus placebo, and improvement in SDS subscale scores significantly predicted functional outcome. Monitoring patient progress early in the course of antidepressant treatment using a functional assessment such as the SDS may help clinicians determine whether or not treatment adjustments are needed.

Received 19 April 2017; Accepted 29 August 2017; First published online 15 November 2017

Key words: Antidepressants, functional outcomes, major depressive disorder, Sheehan Disability Scale, treatment outcome.

\section{Introduction}

Functional impairment is a central feature of major depressive disorder (MDD). ${ }^{1}$ The substantial impact of depression on workplace productivity is welldocumented, ${ }^{2-5}$ and impairment in other domains, including social functioning and home life or family relationships, is commonly observed in patients with MDD. ${ }^{6}$ Among individuals surveyed in the National Comorbidity Survey Replication, 87\% of the 622 respondents who met Diagnostic and Statistical Manual

* Address for correspondence: Claudio N. Soares, Professor of Psychiatry, Queen's University School of Medicine, 76 Stuart Street, Burr 4, Kingston, Ontario, Canada K7L 2V7.

(Email: c.soares@queensu.ca) of Mental Disorders, 4th ed. (DSM-IV), criteria for MDD reported at least moderate impairment in at least one functional domain; for $59 \%$ of respondents with MDD, functional impairment was characterized as severe or very severe. $^{6}$

Functional impairment in patients with MDD seems to improve with treatment along with reduction in depressive symptoms. ${ }^{7,8}$ However, functional recovery may lag behind symptomatic remission, ${ }^{9-11}$ and residual symptoms of depression can delay full functional recovery even in patients who have achieved clinical remission. ${ }^{12}$ Treatment goals for patients with MDD, therefore, should include both symptom remission and functional recovery. ${ }^{13,14}$ Proper management of MDD, including early optimization of treatment, ${ }^{15}$ requires the 
assessment of psychosocial functioning throughout treatment. ${ }^{13,14}$ This means that, in addition to commonly used scales for measuring symptomatic improvement, clinicians should administer instruments designed to assess function in domains that are important to the patient (e.g., work, social, family) in order to monitor functional response to treatment. ${ }^{13,14,16}$

The Sheehan Disability Scale (SDS) is among the most commonly used function scales in clinical trials of antidepressant treatment of MDD. ${ }^{17}$ It is a patient-rated instrument that comprises three domains designed to assess function in work, social life, and family life. ${ }^{18}$ Functional remission has been defined as an SDS total score $\leq 6$, or a score $\leq 2$ on each subscale. ${ }^{19}$ Both mean changes in SDS scores and functional remission rates based on the SDS have been employed to determine the effects of antidepressant treatment on functional impairment associated with depression in clinical trials. ${ }^{20-24}$ Cutler and colleagues ${ }^{25}$ have suggested that examining categorical shifts in improvement on the SDS (rather than simply assessing changes in mean scores) can be useful in assessing clinically meaningful functional improvement in patients treated for depression. Using pooled data from clinical trials of levomilnacipran for the treatment of MDD, they examined proportions of patients who shifted from more severe to less severe categories of functional impairment after 8 or 10 weeks of antidepressant treatment. ${ }^{25}$ When determined early in treatment, categorical shifts based on the SDS might also allow clinicians to better monitor patient progress over time.

Desvenlafaxine (administered as desvenlafaxine succinate) is a serotonin-norepinephrine reuptake inhibitor that has demonstrated antidepressant efficacy in shortand long-term clinical trials. ${ }^{26-29}$ Desvenlafaxine is approved for the treatment of depression in adults with recommended therapeutic doses of 50 and $100 \mathrm{mg} / \mathrm{d} .^{30,31}$ In this post-hoc pooled analysis of eight short-term, placebo-controlled trials of desvenlafaxine for the treatment of MDD, we assessed categorical shifts in SDS scores. In addition, we extended the analysis to examine whether assessment of early improvement in function could inform clinician decisions for optimizing a treatment plan. In other words, what degree of improvement in function can be expected early in treatment, and can the patient's early progress (or lack thereof) indicate whether continuing this treatment is likely to bring the patient to functional recovery? The objectives of our analysis were to evaluate categorical changes in functional impairment measured by the SDS in patients with MDD treated with desvenlafaxine (at the approved doses of $50 \mathrm{or} 100 \mathrm{mg}$ ) compared with placebo and to examine whether improvement in SDS subscale scores early in treatment could predict functional outcomes at study endpoint.

\section{Methods}

\section{Dataset}

This analysis included data pooled from eight multicenter, randomized, double-blind, placebo-controlled studies of desvenlafaxine for the treatment of MDD (Appendix Table 1; see Supplementary Materials for all appendix tables and figures). These comprise all phase 3 , fixed-dose MDD studies including desvenlafaxine 50- and/or 100-mg dose arms conducted by the sponsor (Pfizer Inc) in which the SDS was administered. ${ }^{26,27,32-37}$ Each study was conducted in accordance with the ethical principles that have their origin in the Declaration of Helsinki and was consistent with the principles of good clinical practice and the applicable regulatory requirements in each participating country.

Patients were randomly assigned to receive placebo or a fixed dose of desvenlafaxine $(10,25,50,100,200$, or $400 \mathrm{mg}$ ) in each study (one study included duloxetine $60 \mathrm{mg} / \mathrm{d}$ ), and data from placebo and the desvenlafaxine $50-$ and $100-\mathrm{mg} / \mathrm{d}$ treatment arms were included in the analysis. The studies were similar in design; however, six studies were 8 weeks in duration, one was 10 weeks in duration with a week 8 primary endpoint, and one lasted 12 weeks. The primary efficacy outcome for each study was change from baseline total score on the 17-item Hamilton Rating Scale for Depression ${ }^{38}\left(\mathrm{HAM}-\mathrm{D}_{17}\right)$ at week 8 (except one study, ${ }^{37}$ which had a 12-week primary endpoint). The SDS was administered in each study as a secondary efficacy outcome or health outcome assessment.

\section{Patients}

All studies enrolled adult outpatients with a diagnosis of MDD based on the DSM-IV ${ }^{39}$ or the DSM-IV, Text Revision, ${ }^{40}$ with depressive symptoms for at least 30 days and a minimum baseline $\mathrm{HAM}-\mathrm{D}_{17}$ total score of 20 (six studies) or Montgomery-Åsberg Depression Rating Scale $^{41}$ (MADRS) score of 25 (two studies). One study enrolled perimenopausal and postmenopausal women aged 40 to 70 years $^{36}$; one enrolled gainfully employed patients with an SDS total score $\geq 10$ at both screening and baseline visits. ${ }^{37}$

The exclusion criteria were designed to select a sample of medically stable patients with a primary diagnosis of MDD. Patients with a lifetime diagnosis of bipolar or psychotic disorder or other comorbid psychiatric disorders (except generalized anxiety disorder, panic disorder, or social anxiety disorder, not considered primary) were excluded. Patients with clinically important abnormalities on screening physical examinations, including vital signs and electrocardiograms, were also excluded, as were those who had a significant risk of suicide, current psychoactive substance abuse, or dependence. 


\section{Outcome measures}

The outcome measures for this pooled analysis were the three SDS subscales (work/studies, social life/leisure activities, and family life/home responsibilities) and SDS total score. For each subscale, patients rated the degree to which their activities were disrupted by depression using a scale from 0 to $10(0=$ not at all, $1-3=$ mildly, $4-6=$ moderately, $7-9=$ markedly, and $10=$ extremely). ${ }^{18}$ SDS total score was calculated by summing the subscale scores. SDS total and subscale scores at weeks 2,4 , and 8 were evaluated in this analysis. The timepoint of primary interest was week 8.

\section{Statistical analysis}

The efficacy analysis was performed on the intent-totreat population, defined as all patients who were randomly assigned to treatment, took at least one dose of double-blinded study drug, and had at least one postbaseline $\mathrm{HAM}-\mathrm{D}_{17}$ score.

Shift tables were generated for change in functional impairment category from baseline to week 8, using the last-observation-carried-forward (LOCF) approach for handling missing data. For each subscale, the proportions of patients who shifted functional impairment categories were summarized by treatment group, using the categories of none/mild (0-3), moderate (4-6), and marked/extreme (7-10). ${ }^{25}$ Shifts were also examined for the following endpoints of interest: improvement from moderate/extreme impairment $(\geq 4)$ at baseline to mild/ no impairment $(\leq 3)$ at week $8(\mathrm{LOCF})$; improvement from marked/extreme impairment $(\geq 7)$ at baseline to moderate/no impairment $(\leq 6)$ at week 8 (LOCF); improvement from marked/extreme impairment $(\geq 7)$ at baseline to mild/no impairment $(\leq 3)$ at week $8(\mathrm{LOCF})$; and improvement from baseline of at least one category in all subscales (for patients with $\geq 1$ subscale measured as moderate or higher impairment at baseline). The proportion of patients with worsening function, from moderate/no impairment $(\leq 6)$ at baseline to marked/ extreme impairment $(\geq 7)$ at week $8(\mathrm{LOCF})$, was also assessed.

Treatment comparisons for each of the endpoints of interest were assessed using logistic regression, including treatment group, baseline SDS subscale score, study, and the interactions of treatment group and baseline SDS subscale score as independent variables. If there was no statistically significant interaction effect $(p \geq 0.05$, twosided), the interaction term was dropped from the model; none of the final models included the interaction term. Treatment effects were expressed as the estimated odds ratio $(O R)$ of each active treatment over placebo, and desvenlafaxine $100 \mathrm{mg} / \mathrm{d}$ over desvenlafaxine $50 \mathrm{mg} / \mathrm{d}$.

The predictive value of early improvement in function (change in SDS subscale score) for functional outcome at week 8 (LOCF) was assessed for each SDS subscale in an analysis of the four studies that included the desvenlafaxine 100-mg dose groups. The predictor analysis was conducted based on early improvement at week 2 and repeated based on improvement at week 4 . For each subscale, the outcome of interest was a functional improvement shift from marked/extreme impairment $(\geq 7)$ at baseline to mild/no impairment $(\leq 3)$ at week $8(\mathrm{LOCF})$. Full functional recovery is the ultimate goal of MDD treatment, ${ }^{13,14}$ with functional remission being defined as SDS subscale scores $\leq 2 ;{ }^{19}$ for this particular analysis, we used a shift to mild/no impairment $(\leq 3)$ as the endpoint given the low rates of functional remission at the end of an 8-week trial ${ }^{23}$ and the de-synchronicity between symptomatic remission and functional recovery. ${ }^{9-11}$

A receiver operating characteristic (ROC) analysis was conducted to determine the optimal threshold of early improvement (percentage change from baseline in the SDS subscale score) for predicting achievement of the functional shift threshold for each respective subscale. First, changes in functioning over time were examined in patients included in the ROC analysis (patients with marked/extreme impairment $(\geq 7)$ at baseline). Mean $( \pm S D)$ percentage change from baseline in SDS subscale and total scores were summarized by treatment group. Next, optimal threshold of early improvement were determined using the Max-Min rule. ${ }^{42}$ Sensitivity, specificity, positive predictive value (PPV), and negative predictive value (NPV) were computed for each threshold based on results from logistic regression with a shift to mild/no impairment (yes/no) at week 8 (LOCF) as the dependent variable and percentage change from baseline at week 2 as the independent variable. The proportions of patients who achieved a shift to mild/no impairment $(\leq 3)$ at week 8 (LOCF) was calculated by threshold achievement (yes/no) at week 2 for each subscale. Odds ratios were computed from the logistic regression model to assess the predictability of week 2 improvement on a shift to mild/no impairment at week 8 (LOCF). The predictor analysis was repeated using early improvement at week 4 .

\section{Results}

\section{Patients}

The intent-to-treat population for the eight pooled studies included 3,384 patients (Table 1). Of those, 3,252 patients (desvenlafaxine $50 \mathrm{mg}, n=1,354$; desvenlafaxine $100 \mathrm{mg}, n=568$; placebo, $n=1,330)$ had SDS data at baseline.

Shift analysis at baseline, the percentages of patients in each treatment group who were in the markedly/ extremely impaired category, ranged from 42.3 to $45.6 \%$ for the work subscale, 53.4 to $64.7 \%$ for the social 
subscale, and 49.2 to $59.3 \%$ for the family subscale; 26.5 to $37.7 \%$ were moderately impaired across treatment groups and subscales. At week 8 (LOCF), 47.2 to $55.6 \%$ of desvenlafaxine-treated patients had no/mild impairment (across doses and subscales; placebo, 37.6-42.8\%),

\begin{tabular}{|c|c|c|c|}
\hline Characteristic & $\begin{array}{c}\text { Placebo } \\
n=1,394\end{array}$ & $\begin{array}{c}\text { Desvenlafaxine } \\
\quad 50 \mathrm{mg} \\
n=1,421\end{array}$ & $\begin{array}{c}\text { Desvenlafaxine } \\
\qquad \begin{array}{c}100 \mathrm{mg} \\
n=569\end{array}\end{array}$ \\
\hline \multicolumn{4}{|l|}{ Age, years } \\
\hline Mean $(S D)$ & $43.2(12.8)$ & $43.7(13.0)$ & $42.2(12.7)$ \\
\hline Range & $18-85$ & $18-86$ & $18-78$ \\
\hline \multicolumn{4}{|l|}{ Sex, n (\%) } \\
\hline Female & $949(68.1)$ & 979 (68.9) & $363(63.8)$ \\
\hline \multicolumn{4}{|l|}{ Race, n (\%) } \\
\hline White & 995 (71.4) & $1,029(72.4)$ & $455(80.0)$ \\
\hline $\begin{array}{l}\text { Black or African } \\
\text { American }\end{array}$ & $192(13.8)$ & $217(15.3)$ & $68(12.0)$ \\
\hline Asian & $139(10.0)$ & $132(9.3)$ & $12(2.1)$ \\
\hline Other & $68(4.9)$ & $43(3.0)$ & $34(6.0)$ \\
\hline \multicolumn{4}{|l|}{ Weight, kg } \\
\hline Mean $(S D)$ & $81.6(22.5)$ & $83.4(23.3)$ & $81.7(20.9)$ \\
\hline \multicolumn{4}{|c|}{$\begin{array}{l}\text { Baseline HAM-D }{ }_{17} \text { total } \\
\text { score }\end{array}$} \\
\hline Mean $(S D)$ & $23.1(3.07)$ & $23.0(3.14)$ & $23.7(2.65)$ \\
\hline \multicolumn{4}{|c|}{ Baseline SDS total score } \\
\hline Mean (SD) & $20.0(7.32)$ & $19.5(6.85)$ & $23.2(5.75)$ \\
\hline
\end{tabular}

HAM- $D_{17}=17$-item Hamilton Rating Scale for Depression; $S D=$ standard deviation; SDS = Sheehan Disability Scale. and 27.8 to $32.1 \%$ were moderately impaired (placebo, $33.3-34.7 \%)$.

Among desvenlafaxine-treated patients, 17.3 to $25.2 \%$ of patients, across doses and subscales, shifted from marked/extreme impairment at baseline to no/mild impairment at week 8 (LOCF), compared with 12.7 to $16.3 \%$ of placebo-treated patients across subscales (Table 2). Across SDS subscales, 17.1 to $23.4 \%$ of placebo-treated patients versus 11.6 to $18.4 \%$ of desvenlafaxine-treated patients remained markedly/extremely impaired from baseline to week 8 (LOCF).

Statistically significantly greater proportions of patients in the desvenlafaxine 50- and 100-mg dose groups achieved improvement from baseline to week 8 (LOCF) for each of the prespecified shift endpoints of interest compared with the placebo group (all $p \leq 0.02$; see Table 3 and Figure 1). There were no statistically significant differences between desvenlafaxine dose groups. The odds ratios for categorical improvements in SDS subscales for desvenlafaxine compared with placebo are shown in Figure 2A-C. The proportion of patients with at least one category improvement in each subscale (among patients scoring moderate/ extreme [ $\geq 4$ ] in each scale at baseline) was also significantly greater for the desvenlafaxine groups versus placebo (both $p<0.001$; see Table 3 and Figure 2D).

Significantly smaller proportions of desvenlafaxinetreated patients versus placebo-treated patients worsened on the work/studies and family life/home responsibilities subscales (from moderate/no impairment [ $\leq 6]$ at baseline to marked/extreme impairment $[\geq 7]$ at week 8 [LOCF]; both $p \geq 0.0027$ ); no significant difference was observed for

\begin{tabular}{|c|c|c|c|c|c|c|c|c|c|}
\hline \multirow[b]{3}{*}{ Baseline impairment, $n$ (\%) } & \multicolumn{9}{|c|}{ Week 8 (LOCF) functional impairment } \\
\hline & \multicolumn{3}{|c|}{$\begin{array}{l}\text { Placebo } \\
n=1,389\end{array}$} & \multicolumn{3}{|c|}{$\begin{array}{c}\text { Desvenlafaxine } \\
50 \mathrm{mg} / \mathrm{d} \\
n=1,411\end{array}$} & \multicolumn{3}{|c|}{$\begin{array}{c}\text { Desvenlafaxine } \\
100 \mathrm{mg} / \mathrm{d} \\
n=555\end{array}$} \\
\hline & None/mild & Moderate & Marked/extreme & None/mild & Moderate & Marked/extreme & None/mild & Moderate & Marked/extreme \\
\hline \multicolumn{10}{|l|}{ Work/studies* } \\
\hline None/mild & $191(14.7)$ & $68(5.2)$ & $22(1.7)$ & $196(14.8)$ & $52(3.9)$ & $17(1.3)$ & $80(14.8)$ & $20(3.7)$ & $6(1.1)$ \\
\hline Moderate & $197(15.2)$ & $187(14.4)$ & $67(5.2)$ & $273(20.6)$ & $182(13.7)$ & $44(3.3)$ & $103(19.1)$ & $65(12.0)$ & $20(3.7)$ \\
\hline Marked/extreme & $165(12.7)$ & $177(13.7)$ & $222(17.1)$ & $229(17.3)$ & $178(13.4)$ & $153(11.6)$ & $117(21.7)$ & $65(12.0)$ & $64(11.9)$ \\
\hline \multicolumn{10}{|l|}{ Social life/leisure activities } \\
\hline None/mild & $115(8.3)$ & $43(3.1)$ & $14(1.0)$ & $113(8.0)$ & $41(2.9)$ & $11(0.8)$ & $37(6.7)$ & $10(1.8)$ & $2(0.4)$ \\
\hline Moderate & $181(13.0)$ & $193(13.9)$ & $62(4.5)$ & $258(18.3)$ & $180(12.8)$ & $55(3.9)$ & $85(15.3)$ & $46(8.3)$ & $16(2.9)$ \\
\hline Marked/extreme & $226(16.3)$ & $230(16.6)$ & $325(23.4)$ & $298(21.1)$ & $232(16.4)$ & $223(15.8)$ & $140(25.2)$ & $117(21.1)$ & $102(18.4)$ \\
\hline \multicolumn{10}{|l|}{ Family life/home responsibilities } \\
\hline None/mild & $142(10.2)$ & $48(3.5)$ & $21(1.5)$ & $154(10.9)$ & $48(3.4)$ & $13(0.9)$ & $42(7.6)$ & $10(1.8)$ & $2(0.4)$ \\
\hline Moderate & $202(14.5)$ & $206(14.8)$ & $76(5.5)$ & $270(19.1)$ & $188(13.3)$ & $44(3.1)$ & $97(17.5)$ & $56(10.1)$ & $19(3.4)$ \\
\hline Marked/extreme & $201(14.5)$ & $228(16.4)$ & $265(19.1)$ & $274(19.4)$ & $216(15.3)$ & $204(14.5)$ & $133(24.0)$ & $106(19.1)$ & $90(16.2)$ \\
\hline
\end{tabular}

* Work/studies subscale: placebo, $n=1,296$; desvenlafaxine $50 \mathrm{mg}, n=1,324$; desvenlafaxine $100 \mathrm{mg}, n=540$. LOCF =last observation carried forward; SDS $=$ Sheehan Disability Scale. 
TABLE 3. Proportions of patients with prespecified shifts of interest from baseline

\begin{tabular}{|c|c|c|c|}
\hline & Placebo & $\begin{array}{c}\text { Desvenlafaxine } \\
50 \mathrm{mg}\end{array}$ & $\begin{array}{c}\text { Desvenlafaxine } \\
100 \mathrm{mg}\end{array}$ \\
\hline & $n / N(\%)$ & $n / N(\%)$ & $n / N(\%)$ \\
\hline \multicolumn{4}{|l|}{ Improvement } \\
\hline \multicolumn{4}{|c|}{ Moderate/extreme $(\geq 4)$ to mild/no impairment $(\leq 3)^{*}$} \\
\hline Work/studies & $362 / 1,015(35.7)$ & $502 / 1,059(47.4)^{\dagger}$ & $220 / 434(50.7)^{\dagger}$ \\
\hline Social life/leisure activities & $407 / 1,217(33.4)$ & $556 / 1,246(44.6)^{\dagger}$ & $225 / 506(44.5)^{\dagger}$ \\
\hline Family life/home responsibilities & $403 / 1,178(34.2)$ & $544 / 1,196(45.5)^{\dagger}$ & $230 / 501(45.9)^{\dagger}$ \\
\hline \multicolumn{4}{|c|}{ Marked/extreme $(\geq 7)$ to moderate/no impairment $(\leq 6)^{\ddagger}$} \\
\hline Work/studies & $342 / 564(60.6)$ & $407 / 560(72.7)^{\S}$ & $182 / 246(74.0)^{\dagger}$ \\
\hline Social life/leisure activities & 456/781 (58.4) & $530 / 753(70.4)^{\dagger}$ & $257 / 359(71.6)^{\dagger}$ \\
\hline Family life/home responsibilities & $429 / 694(61.8)$ & 490/694 $(70.6)^{\S}$ & $239 / 329(72.6)^{\dagger}$ \\
\hline \multicolumn{4}{|c|}{ Marked/extreme $(\geq 7)$ to mild/no impairment $(\leq 3)^{\ddagger}$} \\
\hline Work/studies & $165 / 564(29.3)$ & $229 / 560(40.9)^{\dagger}$ & $117 / 246(47.6)^{\dagger}$ \\
\hline Social life/leisure activities & 226/781 (28.9) & $289 / 753(39.6)^{\dagger}$ & $140 / 359(39.0)^{\| \prime}$ \\
\hline Family life/home responsibilities & 201/694 (29.0) & $274 / 694(39.5)^{\dagger}$ & $133 / 329(40.4)^{\S}$ \\
\hline Improved $\geq 1$ category in each subscale ${ }^{\pi}$ & $521 / 1,285(40.5)$ & $686 / 1,318(52.1)^{\dagger}$ & $298 / 543(54.9)^{\dagger}$ \\
\hline \multicolumn{4}{|l|}{ Worsening } \\
\hline \multicolumn{4}{|c|}{ Moderate/no impairment $(\leq 6)$ to marked/extreme impairment $(\geq 7)^{\#}$} \\
\hline Work/studies & 89/732 (12.2) & $61 / 764(8.0)^{\S}$ & $26 / 294(8.8)$ \\
\hline Social life/leisure activities & 76/608 (12.5) & $66 / 658(10.0)$ & 18/196 (9.2) \\
\hline Family life/home responsibilities & $97 / 695(14.0)$ & $57 / 717(8.0)^{\dagger}$ & $21 / 226(9.3)$ \\
\hline \multicolumn{4}{|c|}{ * $n / N=$ number shifted/number moderate/extreme $(\geq 4)$ at baseline. } \\
\hline \multicolumn{4}{|l|}{${ }^{\dagger} p<0.001$ versus placebo. } \\
\hline \multicolumn{4}{|c|}{${ }^{\ddagger} n / N=$ number shifted/number marked/extreme $(\geq 7)$ at baseline. } \\
\hline \multicolumn{4}{|l|}{$\S p<0.01$ versus placebo. } \\
\hline \multicolumn{4}{|l|}{$\| p<0.05$ versus placebo. } \\
\hline \multicolumn{4}{|c|}{${ }^{\pi}$ Among patients scoring moderate/extreme $(\geq 4)$ in each scale at baseline; $n / N=$ number shifted/number moderate/extreme $(\geq 4)$ at baseline. } \\
\hline
\end{tabular}

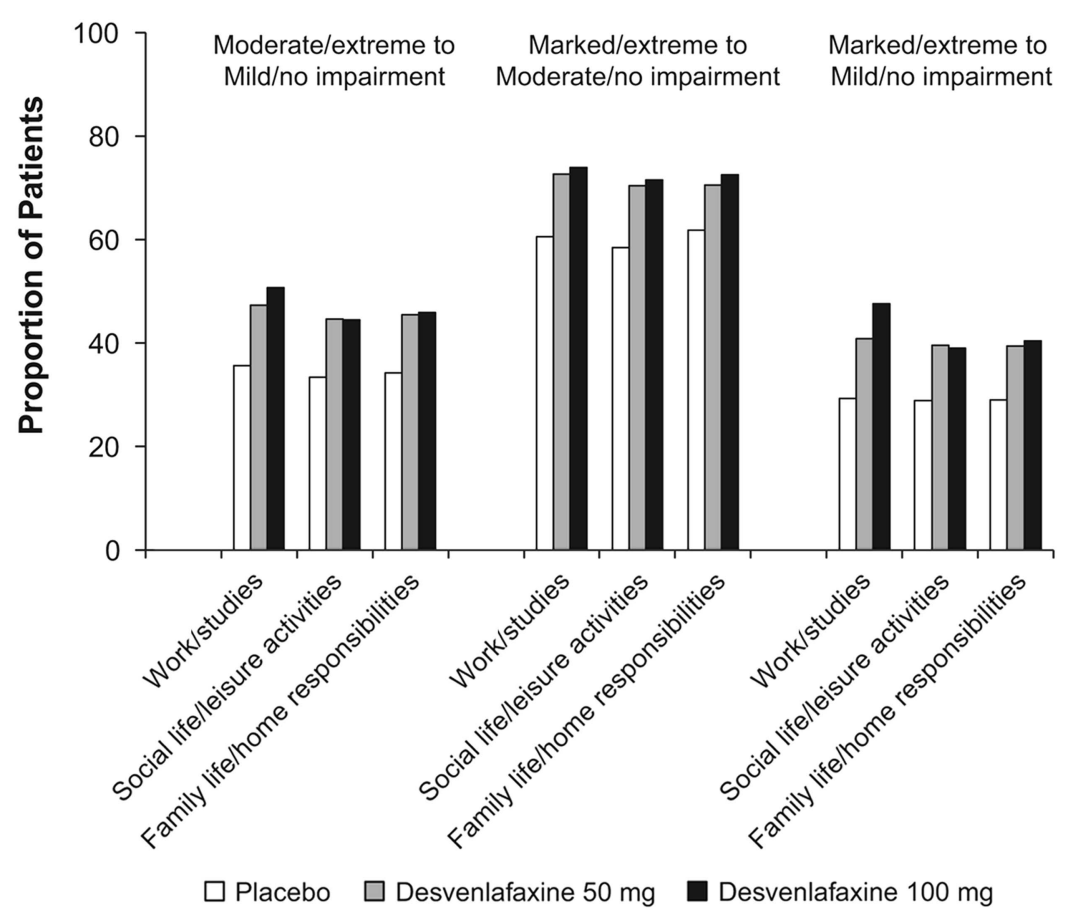

FIGURE 1. Proportions of patients with categorical improvements from moderate/extreme at baseline to mild/no impairment at week 8 (LOCF), from marked/extreme at baseline to moderate/no impairment at week 8 (LOCF), and from marked/extreme at baseline to mild/no impairment at week 8 (LOCF) in each SDS subscale, by treatment group. $\mathrm{LOCF}=$ last observation carried forward; $\mathrm{SDS}=$ Sheehan Disability Scale. ${ }^{*} p<0.001$ vs. placebo; ${ }^{\dagger} p<0.01$ vs. placebo; ${ }^{\ddagger} p<0.05$ vs. placebo. 
A

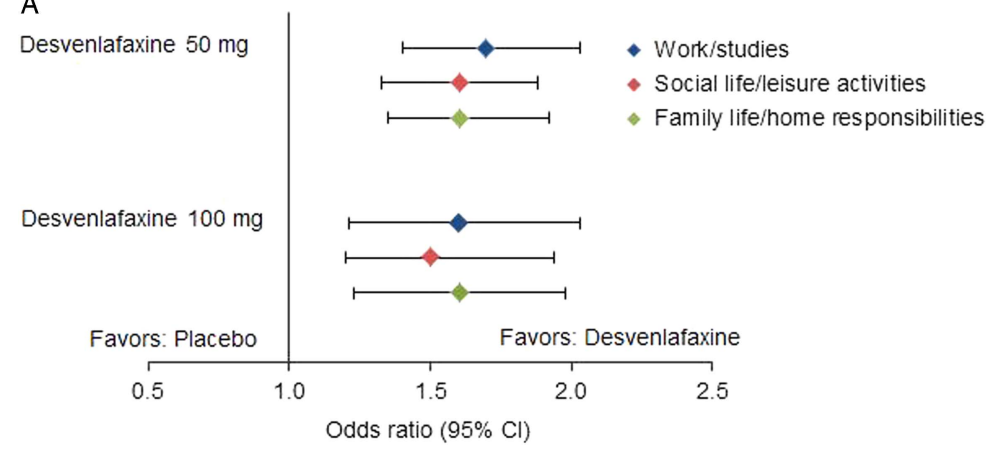

B

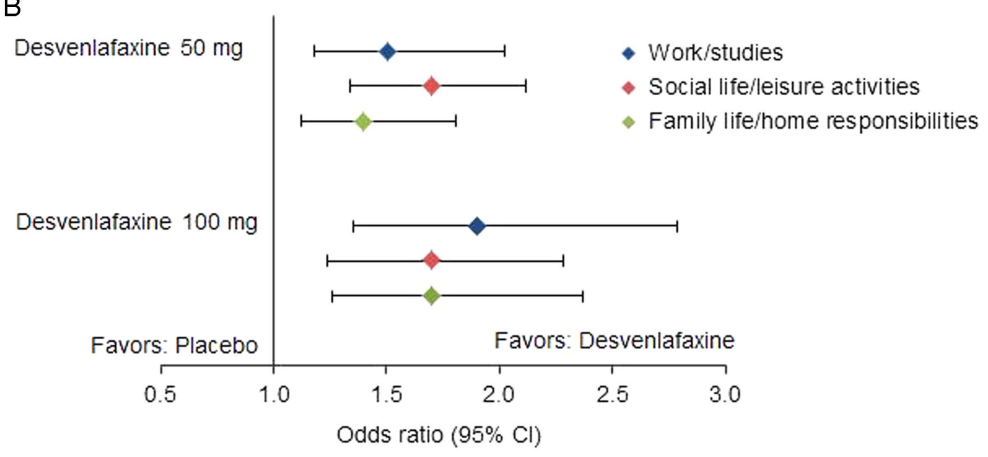

C

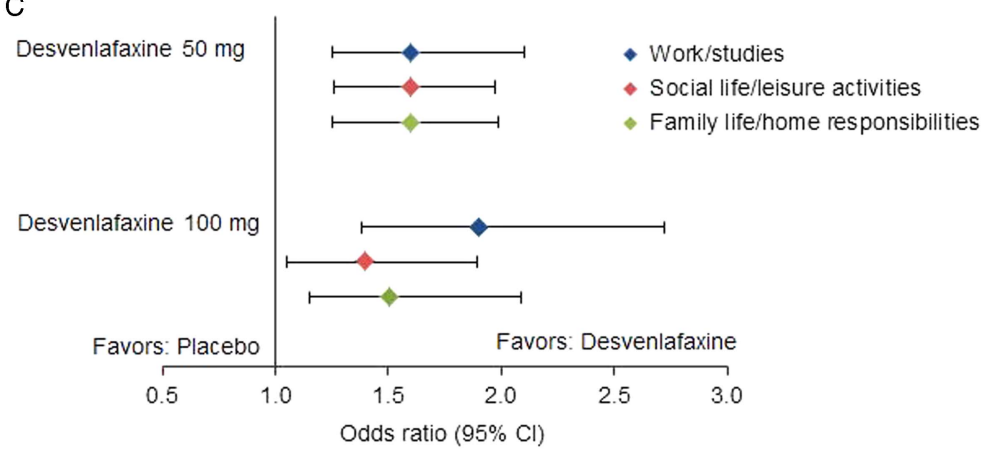

$\mathrm{D}$

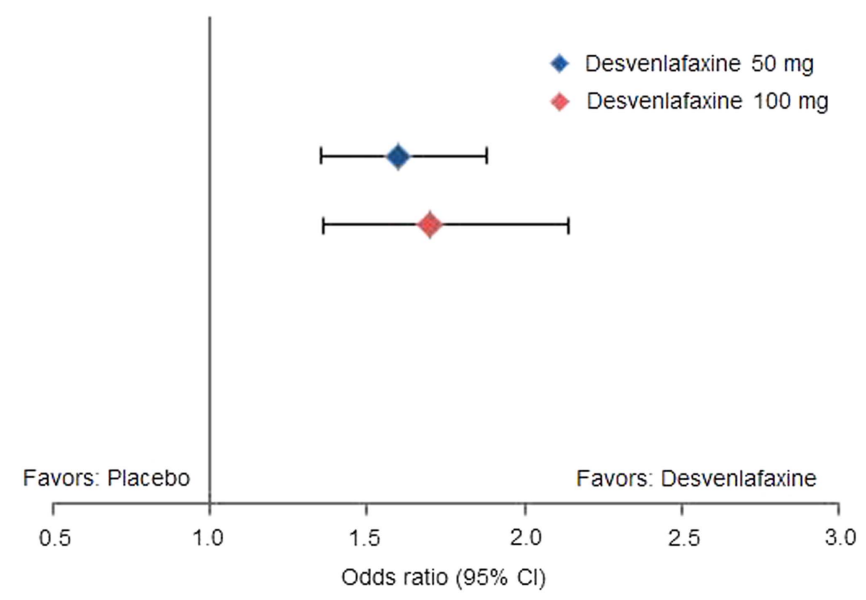

FIGURE 2. Estimated odds ratios for categorical improvements in SDS subscales, desvenlafaxine versus placebo. (A) Improvement from moderate/extreme impairment $(\geq 4)$ at baseline to mild/no impairment ( $\leq 3$ ) at week 8 (LOCF). (B) Improvement from marked/extreme impairment ( $\geq 7$ ) at baseline to moderate/no impairment ( $\leq 6)$ at week 8 (LOCF). (C) Improvement from marked/extreme impairment ( $\geq 7$ ) at baseline to mild/no impairment ( $\leq 3$ ) at week 8 (LOCF). (D) Improvement of $\geq 1$ category in each scale from baseline to week 8 (LOCF). $\mathrm{Cl}=$ confidence interval; LOCF = last observation carried forward; SDS = Sheehan Disability Scale. 

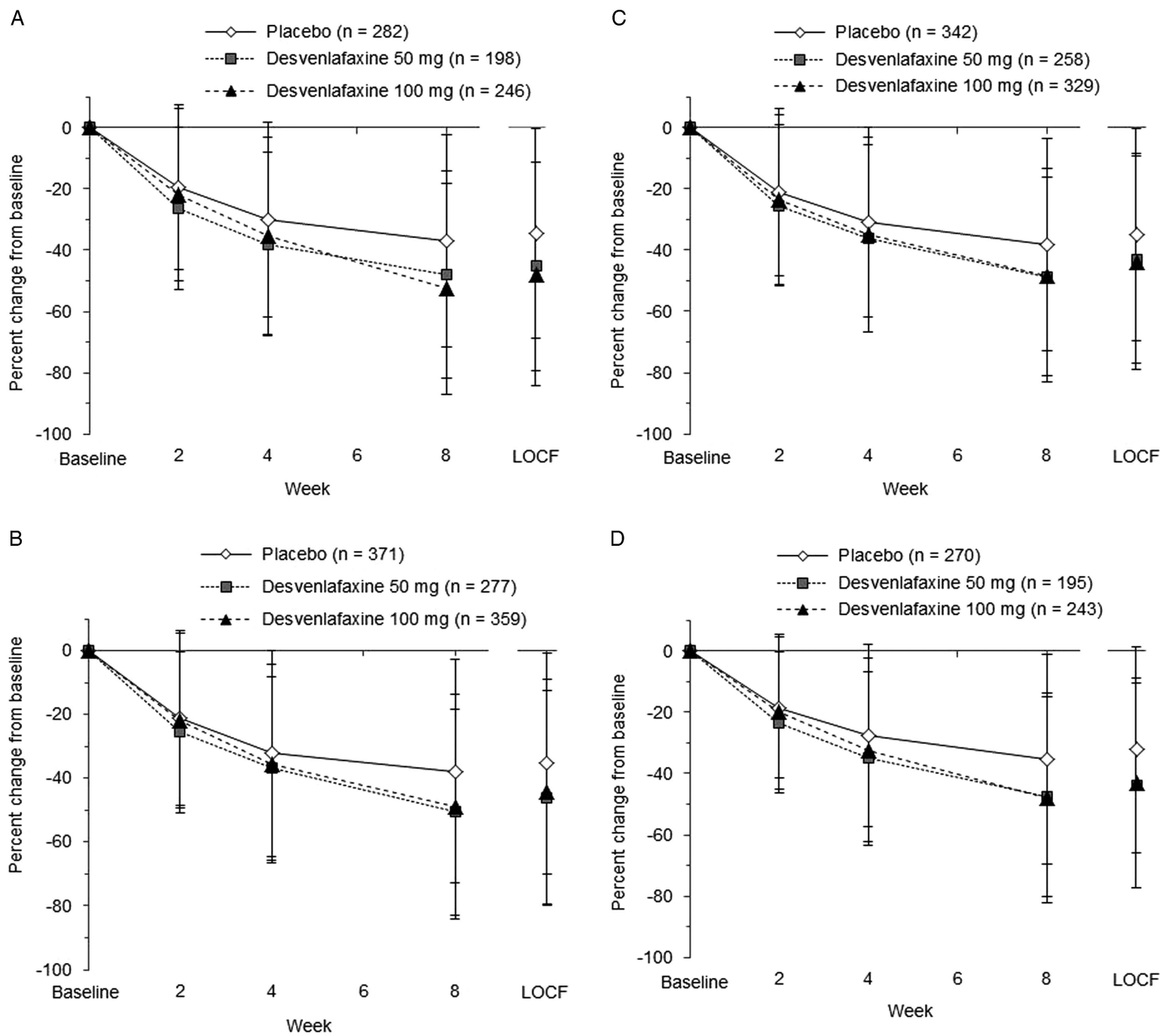

FIGURE 3. Percentage change from baseline over time in SDS total and subscale scores. (A) SDS work/studies score. (B) SDS social life/leisure activities score. (C) SDS family life/home responsibilities score. (D) SDS total score. LOCF = last observation carried forward; SDS = Sheehan Disability Scale.

the social life/leisure activities subscale (Table 3 and Appendix Figure 1). There were no statistically significant differences between the desvenlafaxine 100-mg and placebo groups in the proportions of patients who had worsening of function during treatment on any SDS subscale (Table 3).

\section{Predictor analysis}

The predictive value of early functional improvement (at week 2 or 4) for achievement of a shift to $\mathrm{mild} / \mathrm{no}$ impairment at week 8 (LOCF) was assessed in 1,007 patients with marked/extreme impairment $(\geq 7)$ at baseline (only studies including the desvenlafaxine 100-mg dose). Percentage change from baseline over time in SDS total and subscale scores for those patients is shown in Figure 3. At week 2 , mean percentage change from baseline for the SDS subscale scores ranged from -25.4 to $-26.3 \%$ for desvenlafaxine $50 \mathrm{mg},-21.8$ to $-23.4 \%$ for desvenlafaxine $100 \mathrm{mg}$, and -19.4 to $-21.2 \%$ for placebo.
In the ROC analysis, optimal thresholds of improvement at week 2 for predicting a shift to a score of $\leq 3$ (mild/no impairment) at week 8 (LOCF) from marked/ extreme impairment $(\geq 7)$ at baseline ranged from 14.3 to $28.6 \%$ across treatment groups for the three SDS subscales; for all treatments combined, thresholds ranged from 20 to $25 \%$ (Table 4). Optimal thresholds of improvement at week 4 ranged from 30.0 to $42.9 \%$ (all treatments, 37.5-40\%; Appendix Table 2). Attainment of the threshold of change in SDS subscale score at either week 2 or 4 was a statistically significant predictor of a shift to mild/no impairment at week 8 (LOCF) for all SDS subscales, both overall and for each treatment group (all $p<0.0001$; Appendix Table 3). For all treatments and on all scales, NPV exceeded PPV for early improvement at week $2(\mathrm{NPV}=69.7-84.0, \mathrm{PPV}=49.6-72.6)$ and at week 4 (NPV = 75.7-90.5, PPV = 60.5-78.6). Sensitivity ranged from 62.9 to 76.6 across treatments and subscales for 
TABLE 4. Operating characteristics of improvement at week 2 to predict a shift to mild/no impairment (SDS subscale score $\leq 3$ ) at week 8 (LOCF) for patients with marked/extreme impairment $(\geq 7)$ at baseline: intent-to-treat population

\begin{tabular}{|c|c|c|c|c|c|}
\hline & $\begin{array}{l}\text { Early improvement threshold } \\
\text { (\% decrease) }\end{array}$ & Sensitivity & Specificity & PPV & NPV \\
\hline \multicolumn{6}{|l|}{ Work/studies } \\
\hline Placebo & 22.2 & 65.1 & 71.4 & 51.9 & 81.3 \\
\hline Desvenlafaxine $50 \mathrm{mg} / \mathrm{d}$ & 22.2 & 69.4 & 65.7 & 62.8 & 72.0 \\
\hline Desvenlafaxine $100 \mathrm{mg} / \mathrm{d}$ & 14.3 & 76.6 & 73.0 & 72.6 & 77.1 \\
\hline All & 20.0 & 68.0 & 71.4 & 62.4 & 76.2 \\
\hline \multicolumn{6}{|l|}{ Social life/leisure activities } \\
\hline Placebo & 22.2 & 69.7 & 70.0 & 50.7 & 84.0 \\
\hline Desvenlafaxine $50 \mathrm{mg} / \mathrm{d}$ & 28.6 & 62.9 & 69.7 & 62.9 & 69.7 \\
\hline Desvenlafaxine $100 \mathrm{mg} / \mathrm{d}$ & 22.2 & 68.5 & 73.2 & 63.6 & 77.2 \\
\hline All & 22.2 & 68.7 & 68.0 & 56.9 & 78.0 \\
\hline \multicolumn{6}{|l|}{ Family life/home responsibilities } \\
\hline Placebo & 22.2 & 67.0 & 68.5 & 49.6 & 81.7 \\
\hline Desvenlafaxine $50 \mathrm{mg} / \mathrm{d}$ & 25.0 & 69.5 & 64.9 & 60.8 & 73.1 \\
\hline Desvenlafaxine $100 \mathrm{mg} / \mathrm{d}$ & 22.2 & 70.7 & 68.6 & 61.3 & 76.9 \\
\hline All & 25.0 & 67.1 & 71.0 & 59.0 & 77.6 \\
\hline
\end{tabular}

LOCF = last observation carried forward; NPV = negative predictive value; PPV = positive predictive value; SDS = Sheehan Disability Scale.

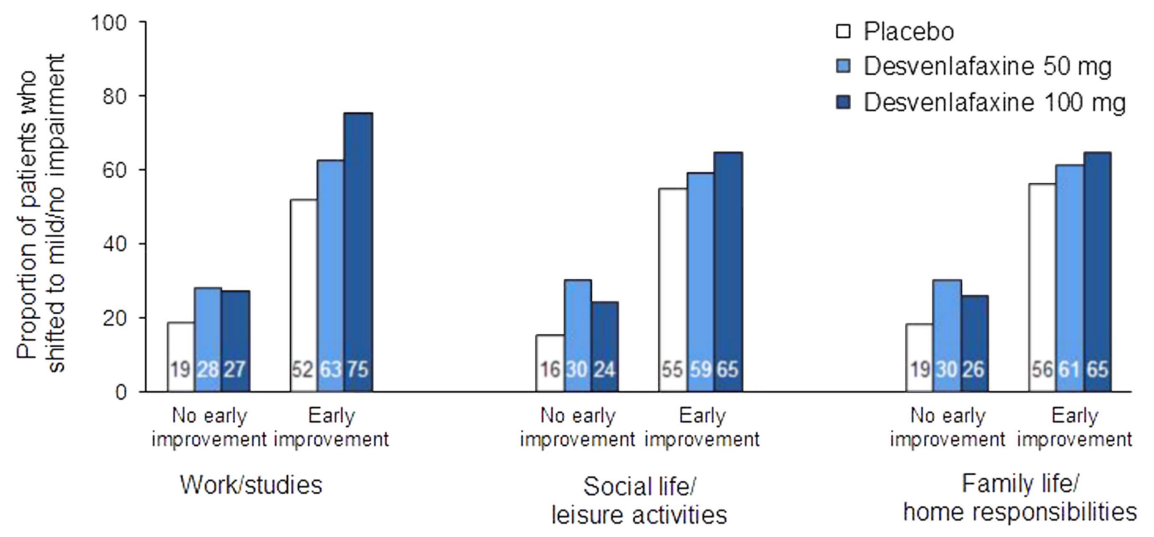

FIGURE 4. Proportions of patients who shifted to mild/no impairment (SDS subscale score $\leq 3$ ) at week 8 (LOCF) by no early improvement vs. early improvement at week 2. Patients with marked/extreme impairment $(\geq 7)$ at baseline only. Early improvement significantly predicted functional response at week 8 (LOCF) on each subscale for all treatment groups (all $p<0.0001$ ). $\mathrm{LOCF}=$ last observation carried forward; SDS $=$ Sheehan Disability Scale.

week 2 improvement, and specificity ranged from 64.9 to 73.2 (74.2-82.1 and 68.4-82.3, respectively, for week 4). The proportions of patients who shifted to mild/no impairment at week 8 (LOCF) were significantly higher among patients who attained the early improvement threshold compared with those who did not $(O R$ [early improvement: yes versus no] $=3.35-8.14$; all $p<0.0001$; see Figure 4 and Appendix Figure 2).

\section{Discussion}

The results of this post-hoc analysis of categorical functional impairment shifts using SDS subscale scores demonstrate that greater proportions of desvenlafaxinetreated patients achieved shifts from marked/extreme impairment to moderate or mild/no impairment compared with placebo-treated patients. The proportions of patients shifting to less severe levels of impairment were significantly greater for desvenlafaxine compared with placebo for all prespecified endpoints: from moderate/extreme $(\geq 4)$ to $\mathrm{mild} /$ no impairment $(\leq 3)$, from marked/extreme $(\geq 7)$ to moderate/no impairment $(\leq 6)$, from marked/extreme $(\geq 7)$ to mild/no impairment $(\leq 3)$, and at least one category improvement in each subscale. Few patients treated with desvenlafaxine had adverse progress throughout treatment (i.e., shifted to poorer functional categories).

The current findings are consistent with those from previous analyses of SDS mean scores in desvenlafaxine trials showing significantly greater improvement from baseline for desvenlafaxine versus placebo. ${ }^{20}$ The use of a 
categorical approach to assess changes in function, however, might provide additional information on how individual patients' functioning evolved over time. ${ }^{25}$ By examining shifts from marked/extreme impairment to moderate/no impairment versus mild/no impairment after 8 weeks of treatment, we addressed questions that are often raised in clinical practice regarding expectations for antidepressant treatment: How likely is a depressed patient with marked/ extreme impairment at baseline to show some improvement to moderate impairment or better over the course of short-term treatment with antidepressants? Would it be realistic to target mild/no impairment after 8 weeks of treatment? In the current analysis, more than $70 \%$ of desvenlafaxine-treated patients reached the first goal (improvement to moderate impairment or better) for each SDS subscale, whereas approximately $40 \%$ of patients reached the goal of mild/no impairment. These results suggest that, for most patients with MDD, a longer course of treatment may be needed to attain complete functional remission. In an analysis with another serotonin-norepinephrine reuptake inhibitor antidepressant (levomilnacipran compared with placebo), a greater percentage of patients with MDD shifted from moderate/extreme or marked/extreme impairment at baseline to mild/no impairment, and from marked/extreme impairment to moderate/ no impairment at study endpoint (week 8 or 10) on each SDS subscale and for SDS total score. ${ }^{25}$

Clinical guidelines for the management of depression emphasize the importance of monitoring response to treatment in the first weeks in order to make critical optimizations or adjustments (when appropriate and needed) as rapidly as possible. ${ }^{13,14}$ There is a growing body of research examining the value of measuring early improvement in depression symptoms to predict clinical efficacy outcomes. ${ }^{15}$ An approximately $20 \%$ improvement from baseline in depression scale scores (e.g., HAM- $\mathrm{D}_{17}$ or MADRS total score) at week 2 significantly predicts clinical efficacy outcomes, such as symptom remission, at study endpoint. ${ }^{15}$ Importantly, analyses have shown that failure to achieve early improvement can be an even stronger predictor of a poor clinical outcome, ${ }^{43,44}$ so that early optimization of treatment may result in faster and better outcomes (e.g., functional recovery). ${ }^{15} \mathrm{In}$ a previous analysis of data from desvenlafaxine trials, we found that early improvement in SDS total score at week 2 was a significant predictor of functional response or remission based on SDS total score (SDS total score $\leq 12$ and $<7$, respectively), as well as combined functional/symptomatic remission (SDS total score $<7$ and HAM-D $\mathrm{D}_{17}$ total score $\leq 7$ ) at week $8 .^{23}$ The results of the current predictor analysis further demonstrate that functional improvement at week 2 (or week 4) significantly predicts a shift in categorical measures of functioning-namely, from marked/extreme impairment $(\geq 7)$ at baseline to mild/no impairment $(\leq 3)$ for each SDS subscale. Based on the ROC analysis, the optimal threshold of improvement at week 2 for predicting functional outcome in this patient sample was approximately 20 to $25 \%$, which would correspond to roughly a 1 - to 2-point improvement in a subscale score for patients with marked impairment at baseline. Thus, failure to show a 1- to 2-point improvement on SDS subscales after 2 weeks of treatment suggests that the patient may need a treatment adjustment in order to eventually achieve full functional recovery. At week 4, an improvement of approximately 3 points on an SDS subscale ( $\approx 30-40 \%$ improvement from baseline) also significantly predicts functional outcome, with a higher sensitivity and specificity compared with achievement of the 2-week threshold.

This post-hoc analysis had several limitations. First, this analysis was based on data pooled from multiple studies, which had some differences in design (e.g., number of treatment arms, duration of treatment, enrollment criteria). Also, none of the pooled studies was originally designed to assess functioning (i.e., SDS) as a primary endpoint. The generalizability of the current results is also limited by the sample characteristics: patients with few significant medical or psychological comorbidities were enrolled in the pooled studies. Finally, it would be of interest to fully explore the relationship between shifts in functioning and improvements in depressive symptoms over the course of antidepressant treatment. In a previous post-hoc analysis of a desvenlafaxine trial, early improvement in depressive symptoms was a significant predictor of SDS total score at week $12 .{ }^{45}$ Although outside the scope of the current analysis, future studies could better determine the association and timing of shifts in functioning as they relate to changes in symptom severity.

\section{Conclusions}

Categorical improvements in functional impairment, as measured by shifts in SDS subscale scores, were observed in greater percentages among patients treated with desvenlafaxine 50 or $100 \mathrm{mg} / \mathrm{d}$ compared with those who received placebo. Improvement in SDS subscale scores significantly predicted functional outcomes. The optimal early improvement threshold for predicting mild/no impairment at week 8 (LOCF) was an approximately 20 to $25 \%$ change, or a 1 - to 2-point improvement, from baseline at week 2 . These results suggest a potential role for early monitoring of functioning (in addition to symptomatic relief) in the course of antidepressant treatment; for that, the use of measures such as the SDS may help clinicians determine sooner than later whether treatment adjustments are needed.

\section{Disclosures}

Dr. Soares reports grants from the Ontario Brain Institute; from the Ontario Ministry of Research, Innovation, 
and Science; from the Canadian Network for Biomarker Integration in Depression; and personal fees from Pfizer.

Min Zhang is an employee of Pfizer.

Dr. Boucher is an employee of Pfizer Canada and owns Pfizer stock and stock options.

This study was sponsored by Pfizer Inc. Medical writing support was provided by Kathleen M. Dorries, $\mathrm{PhD}$, of Peloton Advantage and was funded by Pfizer. The authors, however, are entirely responsible for the scientific content of the paper.

Clinical trial registration: NCT00072774, NCT00277823, NCT00300378, NCT00384033, NCT00798707, NCT00863798, NCT01121484, and NCT00824291 (ClinicalTrials.gov).

\section{SUPPLEMENTARY MATERIAL}

To view supplementary materials for this article, please visit https://doi.org/10.1017/S10928529 17000633

\section{REFERENCES:}

1. American Psychiatric Association. Diagnostic and Statistical Manual of Mental Disorders, 5th ed. Arlington, VA: American Psychiatric Association; 2013: 160-168.

2. Lerner D, Adler DA, Chang H, et al. Unemployment, job retention and productivity loss among employees with depression. Psychiatr Serv. 2004; 55(12): 1371-1378.

3. Jain G, Roy A, Harikrishnan V, Yu S, Dabbous O, Lawrence C. Patientreported depression severity measured by the PHQ-9 and impact on work productivity: results from a survey of full-time employees in the United States. J Occup Environ Med. 2013; 55(3): 252-258.

4. Beck A, Crain LA, Solberg LI, et al. The effect of depression treatment on work productivity. Am J Manag Care. 2014; 20(8): e294-e301.

5. Asami Y, Goren A, Okumura Y. Work productivity loss with depression, diagnosed and undiagnosed, among workers in an internet-based survey conducted in Japan. J Occup Environ Med. 2015; 57(1): 105-110

6. Kessler RC, Berglund P, Demler O, et al. The epidemiology of majo depressive disorder: results from the National Comorbidity Survey Replication (NCS-R). JAMA.. 2003; 289(23): 3095-3105.

7. Guico-Pabia CJ, Fayyad RS, Soares CN. Assessing the relationship between functional impairment/recovery and depression severity: a pooled analysis. Int Clin Psychopharmacol. 2012; 27(1): 1-7.

8. Dennehy EB, Marangell LB, Martinez J, Balasubramani GK, Wisniewski SR. Clinical and functional outcomes of patients who experience partial response to citalopram: secondary analysis of STAR ${ }^{*}$ D. J Psychiatr Pract. 2014; 20(3): 178-187.

9. Sheehan DV, Chokka PR, Granger RE, Walton RJ, Raskin J, Sagman D. Clinical and functional outcomes in patients with major depressive disorder and painful physical symptoms switched to treatment with duloxetine. Hum Psychopharmacol. 2011; 26(3): 242-251.

10. van der Voort TY, Seldenrijk A, van MB, et al. Functional versus syndromal recovery in patients with major depressive disorder and bipolar disorder. J Clin Psychiatry. 2015; 76(6): e809-e814.

11. Rush AJ. Distinguishing functional from syndromal recovery: implications for clinical care and research. J Clin Psychiatry. 2015; 76(6): e832-e834.
12. Zajecka J, Kornstein SG, Blier P. Residual symptoms in major depressive disorder: prevalence, effects, and management. J Clin Psychiatry. 2013; 74(4): 407-414.

13. Gelenberg AJ, Freeman MP, Markowitz JC, et al. Practice Guideline for the Treatment of Patients with Major Depressive Disorder. Arlington, VA: American Psychiatric Association http:// psychiatryonline.org/pb/assets/raw/sitewide/practice_guidelines/ guidelines/mdd.pdf. Accessed September 7, 2017.

14. Lam RW, McIntosh D, Wang J, et al. Canadian Network for Mood and Anxiety Treatments (CANMAT) 2016 clinical guidelines for the management of adults with major depressive disorder, section 1: disease burden and principles of care. Can J Psychiatry. 2016; 61(9): 510-523.

15. Habert J, Katzman MA, Oluboka OJ, et al. Functional recovery in major depressive disorder: focus on early optimized treatment. Prim Care Companion CNS Disord. 2016; 18(5): http://www.psychiatrist. com/PCC/article/Pages/2016/v18n05/15r01926.aspx. Accessed September 7, 2017.

16. Lam RW, Filteau MJ, Milev R. Clinical effectiveness: the importance of psychosocial functioning outcomes. J Affect Disord. 2011; 132 (Suppl 1): S9-S13.

17. Sheehan DV, Nakagome K, Asami Y, Pappadopulos EA, Boucher M. Restoring function in major depressive disorder: a systematic review. J Affect Disord. 2016; 215: 299-313.

18. Sheehan DV, Harnett-Sheehan K, Raj BA. The measurement of disability. Int Clin Psychopharmacol. 1996; 11(Suppl 3): 89-95.

19. Sheehan KH, Sheehan DV. Assessing treatment effects in clinical trials with the discan metric of the Sheehan Disability Scale. Int Clin Psychopharmacol. 2008; 23(2): 70-83.

20. Soares CN, Kornstein SG, Thase ME, Jiang Q, Guico-Pabia CJ. Assessing the efficacy of desvenlafaxine for improving functioning and well-being outcome measures in patients with major depressive disorder: a pooled analysis of 9 double-blind, placebo-controlled, 8-week clinical trials. J Clin Psychiatry. 2009; 70(10): 1365-1371.

21. Oakes TM, Myers AL, Marangell LB, et al. Assessment of depressive symptoms and functional outcomes in patients with major depressive disorder treated with duloxetine versus placebo: primary outcomes from two trials conducted under the same protocol. Hum Psychopharmacol. 2012; 27(1): 47-56.

22. Sambunaris A, Gommoll C, Chen C, Greenberg WM. Efficacy of levomilnacipran extended-release in improving functional impairment associated with major depressive disorder: pooled analyses of five double-blind, placebo-controlled trials. Int Clin Psychopharmacol. 2014; 29(4): 197-205.

23. Soares CN, Endicott J, Boucher M, Fayyad RS, Guico-Pabia CJ. Predictors of functional response and remission with desvenlafaxine $50 \mathrm{mg} / \mathrm{d}$ in patients with major depressive disorder. CNS Spectr. $2014 ;$ 19(6): 519-527.

24. Mancini M, Sheehan DV, Demyttenaere K, et al. Evaluation of the effect of duloxetine treatment on functioning as measured by the Sheehan disability scale: pooled analysis of data from six randomized, double-blind, placebo-controlled clinical studies. Int Clin Psychopharmacol. 2012; 27(6): 298-309.

25. Cutler AJ, Gommoll CP, Chen C, Greenberg WM, Ruth A. Levomilnacipran extended-release treatment in patients with major depressive disorder: improvements in functional impairment categories. Prim Care Companion CNS Disord. 2015; 17(3): https://www.ncbi.nlm.nih.gov/pmc/articles/PMC4578909/. Accessed September 7, 2017.

26. Boyer P, Montgomery S, Lepola U, et al. Efficacy, safety, and tolerability of fixed-dose desvenlafaxine 50 and $100 \mathrm{mg} /$ day for major depressive disorder in a placebo-controlled trial. Int Clin Psychopharmacol. 2008; 23(5): 243-253.

27. Iwata N, Tourian KA, Hwang E, Mele L, Vialet C. Efficacy and safety of desvenlafaxine 25 and $50 \mathrm{mg}$ /day in a randomized, placebocontrolled study of depressed outpatients. J Psychiatr Pract. 2013; 19(1): 5-14. 
28. Clayton A, Tourian KA, Focht K, Hwang E, Cheng RF, Thase ME. Desvenlafaxine 50- and 100-mg/d vs. placebo for the treatment of major depressive disorder: a phase 4, randomized controlled trial. J Clin Psychiatry. 2015; 76(5): 562-529.

29. Rosenthal JZ, Boyer P, Vialet C, Hwang E, Tourian KA. Efficacy and safety of desvenlafaxine $50 \mathrm{mg} / \mathrm{d}$ for prevention of relapse in major depressive disorder: a randomized controlled trial. J Clin Psychiatry. 2013; 74(2): 158-166.

30. Pristiq package insert. Philadelphia: Wyeth Pharmaceuticals Inc., a subsidiary of Pfizer; 2016.

31. Pristiq product monograph. Kirkland, Quebec: Pfizer Canada; 2016

32. DeMartinis NA, Yeung PP, Entsuah R, Manley AL. A double-blind, placebo-controlled study of the efficacy and safety of desvenlafaxine succinate in the treatment of major depressive disorder. J Clin Psychiatry. 2007; 68(5): 677-688.

33. Liebowitz MR, Manley AL, Padmanabhan SK, Ganguly R, Tummala R, Tourian KA. Efficacy, safety, and tolerability of desvenlafaxine $50 \mathrm{mg} /$ day and $100 \mathrm{mg}$ /day in outpatients with major depressive disorder. Curr Med Res Opin. 2008; 24(7): 1877-1890.

34. Tourian KA, Padmanabhan SK, Groark J, Brisard C, Farrington D. Desvenlafaxine 50 and $100 \mathrm{mg} / \mathrm{d}$ in the treatment of major depressive disorder: an 8-week, phase III, multicenter, randomized, double-blind, placebo-controlled, parallel-group trial and a post hoc pooled analysis of three studies. Clin Ther. 2009; 31(Pt 1): 1405-1423.

35. Liebowitz MR, Tourian KA, Hwang E, Mele L. A double-blind, randomized, placebo-controlled study assessing the efficacy and tolerability of desvenlafaxine 10 and $50 \mathrm{mg} / \mathrm{d}$ in adult outpatients with major depressive disorder. BMC Psychiatry. 2013; 13(1): 94 https://www.ncbi.nlm.nih.gov/pmc/articles/PMC3763843/. Accessed September 7, 2017.

36. Clayton AH, Kornstein SG, Dunlop BW, et al. Efficacy and safety of desvenlafaxine $50 \mathrm{mg} / \mathrm{d}$ in a randomized, placebocontrolled study of perimenopausal and postmenopausal women with major depressive disorder. J Clin Psychiatry. 2013; 74(10): 1010-1017.

37. Dunlop BW, Reddy S, Yang L, Lubaczewski S, Focht K, Guico-Pabia CJ. Symptomatic and functional improvement in employed depressed patients: a double-blind clinical trial of desvenlafaxine versus placebo. J Clin Psychopharmacol. 2011; 31(5): 569-576.

38. Hamilton M. A rating scale for depression. J Neurol Neurosurg Psychiatry. 1960; 23: 56-62.

39. American Psychiatric Association. Diagnostic and Statistical Manual of Mental Disorders, 4th ed. Washington, DC: American Psychiatric Publishing; 1994.

40. American Psychiatric Association. Diagnostic and Statistical Manual of Mental Disorders, Text Revision, 4th ed. Washington, DC: American Psychiatric Publishing; 2000.

41. Montgomery SA, Åsberg M. A new depression scale designed to be sensitive to change. Br J Psychiatry. 1979; 134: 382-389.

42. Gallop RJ. Determination and interpretation of the OOP for ROC's with PROC LOGISTIC. Baltimore: NorthEast SAS Users Group; 2001. http://www.lexjansen.com/nesug/nesug01/st/st9006r.pdf. Accessed September 7, 2017.

43. Tohen M, Case M, Trivedi MH, Thase ME, Burke SJ, Durell TM. Olanzapine/fluoxetine combination in patients with treatmentresistant depression: rapid onset of therapeutic response and its predictive value for subsequent overall response in a pooled analysis of 5 studies. J Clin Psychiatry. 2010; 71(4): 451-462.

44. Soares CN, Fayyad RS, Guico-Pabia CJ. Early improvement in depressive symptoms with desvenlafaxine $50 \mathrm{mg} / \mathrm{d}$ as a predictor of treatment success in patients with major depressive disorder. J Clin Psychopharmacol. 2014; 34(1): 57-65.

45. Lam RW, Endicott J, Hsu MA, Fayyad R, Guico-Pabia C, Boucher M. Predictors of functional improvement in employed adults with major depressive disorder treated with desvenlafaxine. Int Clin Psychopharmacol. 2014; 29(5): 239-251. 